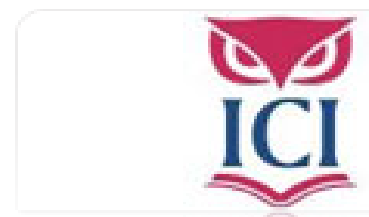

IUS. Revista del Instituto de Ciencias Jurídicas de Puebla A.C.

\title{
ISSN: $1870-2147$
}

revista.ius@hotmail.com

Instituto de Ciencias Jurídicas de Puebla A. C.

México

Viciano Pastor, Roberto

Reflexiones sobre la coyuntura constitucional y política en Venezuela (los problemas de una postura crítica frente a la reforma constitucional)

IUS. Revista del Instituto de Ciencias Jurídicas de Puebla A.C., núm. 21, 2008, pp. 285-297 Instituto de Ciencias Jurídicas de Puebla A. C.

Puebla, México 


\section{Reflexiones sobre la coyuntura constitucional y política en Venezuela (los problemas de una postura crítica frente a la reforma constitucional)}

Roberto Viciano Pastor*

$\mathrm{E}$ domingo 2 de diciembre de 2007 el pueblo venezolano ha sido convocado a las urnas para decidir la aprobación o el rechazo de la reforma constitucional que ha planteado la mayoría del bloque de fuerzas políticas que apoyan al presidente Chávez. Como no podía ser de otro modo, dada la cantidad de cuestiones de gran trascendencia que se están ventilando con esta decisión y la falta del tiempo suficiente para explicar y debatir cada una de ellas, la campaña electoral no ha dejado mucho espacio para una reflexión ponderada. Como ha ocurrido desde las primeras elecciones que ganó Hugo Chávez, nueve años atrás, el pueblo venezolano ha vuelto a seccionarse en dos posiciones, que parecieran irreconciliables si no fuera porque quienes conocemos bien el país sabemos de su enorme capacidad para transitar de la más alta crispación al más cariñoso trato.

En esta ocasión, sin embargo,

* Profesor titular de derecho constitucional de la Universitat de Valencia. se produce una novedad que no se ha dado en otras ocasiones anteriores. Aunque este artículo se escribe cuando aún no se conocen los resultados de la jornada electoral, todo parece indicar que una parte significativa del chavismo no se ha alineado con su máximo dirigente. Sean los resultados que fueren, lo cierto es que el partido socialdemócrata podemos, diversos académicos de izquierda y los sectores vinculados al trostskismo y a la izquierda radical, aliados desde el principio al proyecto de cambio liderado por Hugo Chávez, se han posicionado en contra de la reforma constitucional. Y también lo han hecho personas que apoyaron el proceso de diferentes maneras, entre ellas el general Baduel, compañero de Chávez en el ejército y uno de los principales oficiales que organizaron la resistencia militar frente a aquel golpe de Estado que promovió la derecha venezolana e internacional en 2002 contra Chávez, y que instauró brevemente una dictadura encabezada por el presidente de la patronal venezolana, Pedro Carmona. Unos desde la confluencia en el objetivo de generar un modelo socialista y Baduel desde el rechazo al proyecto socialista.

Desde la restitución del presidente constitucional, esa derecha no ha cesado de intentar derrocar a Chávez, con ayuda de capital norteamericano y europeo, utilizando métodos democráticos y no tan de- 
mocráticos: repetidos intentos de magnicidio, nuevas tentativas de golpe de Estado, cierres patronales... y haciendo uso, siempre, de una maquinaria propagandística internacional que ha buscado degenerar hasta el extremo la imagen de Hugo Chávez y de la revolución bolivariana.

Por esa razón, resulta especialmente complicado tomar posición sobre cuestiones clave que acaecen en Venezuela. En esa situación frentista, donde además los medios de comunicación manipulan la información a su antojo y la difunden con una carga considerable de falsedad, cualquier crítica al gobierno del presidente Chávez puede ser objeto de uso por parte de una oposición que, fuera de sí, inevitablemente intentará convertir cualquier discrepancia en nueva munición contra el proceso político y social bolivariano.

Éstas son las razones que han llevado a que hayamos esperado a este día crucial, para que antes de que se conozcan los resultados del referéndum hacer pública una postura sobre la reforma constitucional que hoy se dilucida, y opinar sobre el rumbo que puede tomar el proceso político y social venezolano. Debe hacerse constar que esta posición crítica se hizo llegar oportuna y reservadamente en el mes de octubre de este año, en un informe que elaboramos más de una docena de profesores universitarios españo- les, a las más altas instancias de gobierno de la República Bolivariana de Venezuela.

Pero, a pesar de que desde bien temprano manifestamos nuestra postura crítica con el proyecto de reforma constitucional, preferimos permanecer al margen del debate constitucional con el fin de que nuestra discrepancia no fuera utilizada malintencionadamente por la derecha golpista venezolana y el aparato mediático de dominación.

Por esa razón, cuando nos encontramos ante la que quizá sea la más disputada batalla electoral de la Quinta República venezolana, sin que pueda saberse a ciencia cierta de qué lado se inclinará la balanza, nos ha parecido el momento adecuado para hacer pública nuestra posición y algunas reflexiones sobre la encrucijada política y social en que se encuentra el proceso bolivariano.

Como suele suceder con quienes intentan plantear posiciones reflexivas y equilibradas en momentos de fuerte confrontación, es muy probable que concitemos el rechazo de ambos sectores. Los unos porque alegarán que debimos plantear públicamente estas cuestiones antes y los otros porque pueden entender que nunca debieron publicitarse.

Pero estamos convencidos de que la construcción de un modelo de socialismo del siglo xxI requiere de estos debates y, sobre todo, esperamos que ese nuevo socialismo que 
se intenta construir en Venezuela aprenda de la Historia que sólo desde el pluralismo, la contraposición de puntos de vista y la libertad de pensamiento y de expresión se puede construir un socialismo emancipador. La existencia de una presión interna y externa, incluso de una agresión interna o externa, no pueden justificar la eliminación de esos principios básicos de organización política. Pues supondría reconocer que cualquier intento de construcción del socialismo, que necesariamente tendrá fuertes resistencias internas y externas, tiene que pasar por el autoritarismo y el recorte de libertades. Y eso no es así. Como precisamente ha quedado demostrado en Venezuela hasta el momento, los procesos políticos que cuentan con apoyo popular pueden sobrevivir a las presiones internas y externas con pluralismo y dentro de un marco ejemplar de respeto a los derechos y las libertades públicas.

\section{¿Era necesaria esta reforma constitucional?}

Un hecho sustancial que no puede ser dejado de lado en este análisis es que, para muchos de los partidarios del proceso bolivariano, esta reforma constitucional no era necesaria, al menos en estos términos. Y ello por varias razones.

En primer lugar, porque se podía haber avanzado aún mucho más en el diseño del nuevo Estado por la vía legal y reglamentaria sin necesidad, de momento, de cambiar el texto constitucional.

En segundo lugar, porque para una gran cantidad de venezolanos y venezolanas el proceso bolivariano aún tiene muchas cuestiones que resolver de su gestión cotidiana del poder. Los problemas que acucian al país no son, desde luego, atípicos. Las últimas encuestas son claras: la inseguridad ciudadana, la inflación, el desempleo, la corrupción y el peligro de una fractura definitiva en el pueblo son las cuestiones que preocupan a las venezolanas y los venezolanos, y que deberían preocupar aún más a los poderes públicos antes que otras cuestiones quizás más pomposas, pero desde luego secundarias.

En tercer lugar, porque aún no está bien definido qué se entiende por socialismo del siglo xxI y cuáles son sus aplicaciones políticas y económico-sociales concretas y en detalle. Además, la generación del socialismo no puede hacerse por decreto, ni siquiera por reforma constitucional. Hace falta una conciencia social que soporte el proceso y lo asuma conscientemente. Parece claro que en una sociedad como la venezolana, formada durante decenios en el más puro individualismo, ese presupuesto no existe aún.

En cuarto lugar, porque para afrontar una transformación social profunda en sentido socialista debe contarse con un Estado fuerte y que 
funcione adecuadamente, cosa que como es obvio, no ocurre en Venezuela.

Si la cuestión políticamente urgente era, ante la necesidad de una dirección carismática del proceso, la autorización constitucional de la posibilidad de que Hugo Chávez pueda presentarse a presidente de la República tantas veces como lo considere oportuno y pueda ser presidente tantas veces como el pueblo venezolano libremente así lo decida, debería de haberse planteado esa exclusiva cuestión que, como indican todas las encuestas electorales, contaba con un amplio apoyo popular.

Y sobre todo, una vez decidido que se iba a realizar un proceso de reforma, se entendía que debía ser para profundizar en los grandes principios de la Constitución de 1999: más democracia, más controles sobre el poder, profundización de los derechos y las libertades, más control de las disfunciones del mercado y más medidas de generación de una nueva economía autónoma del monocultivo petrolero.

Indudablemente, mucha gente no ha percibido que la reforma reforzaba todos estos ejes.

\section{¿Reforma constitucional o} Asamblea Nacional Constituyente?

Con independencia de todo lo dicho hasta ahora con carácter previo, y asumiendo que la decisión política de la dirección del proceso bolivariano era la de proceder a una amplia reforma, nos encontramos con la segunda cuestión: ¿se ha utilizado la vía constitucional adecuada?

Si partimos de que el poder constituyente sólo puede ser ejercido por su titular, el pueblo, cualquier cambio en el texto constitucional debe ser autorizado por el poder constituyente. Éste es el caso de la reforma constitucional en Venezuela; el buen criterio de los constituyentes venezolanos de 1999 eliminó el supuesto poder constituyente constituido o poder de reforma constitucional ejercido por el poder constituido, y ni una coma ni un punto de la Constitución puede ser cambiado sin el consentimiento del pueblo, en ejercicio genuino del poder constituyente. Por tanto, en Venezuela es indudable que una reforma constitucional sólo puede culminar con éxito cuando el pueblo así lo desee.

Sin embargo, el problema reside en el procedimiento que debería haberse empleado para llevar adelante una modificación de la Constitución de estas dimensiones en extensión y contenidos. Reformas de gran calado, como la propia Constitución de 1999 indica -artículo 347 en relación con el 342-, deberían debatirse no en el seno de los poderes constituidos, sino de una Asamblea Nacional Constituyente. El artículo 342 es taxativo cuando establece que la reforma constitucional "tie- 
ne por objeto una revisión parcial de esta Constitución y la sustitución de una o varias de sus normas que no modifiquen la estructura y principios fundamentales del texto constitucional" mientras que la Asamblea Nacional Constituyente queda reservada para los supuestos excluidos o la redacción de una nueva Constitución.

Para cualquier lector de la propuesta de reforma, resulta evidente que un cambio que propone modificar 69 artículos de la Constitución vigente, y que lo hace para construir, donde antes se hablaba de una Democracia participativa, una Democracia socialista (artículo 158); o que habla de Estado socialista (artículo 318) donde antes sólo se hacía referencia al Estado Democrático y Social de Derecho; o que prevé que el Ejecutivo Nacional pueda regular la transición al modelo de Economía Socialista (artículo 300 y disposición transitoria novena), es de suficiente envergadura para ser debatido con amplitud en el seno más democrático donde pueda acontecer este debate: una Asamblea Constituyente.

$\mathrm{Si}$ esas definiciones no bastaran para entender que estamos ante una modificación de los principios fundamentales del texto constitucional, la reforma afronta la modificación del artículo 16 de la vigente Constitución para la generación de nuevas estructuras territoriales antes inexistentes, como regiones marítimas, municipios federales, distritos funcionales, ciudades comunales...; reformula el contenido constitucional de diversos derechos políticos y sociales, entre ellos el de propiedad (artículo 115); se elimina un órgano de relieve constitucional como el Consejo Federal de Gobierno (artículo 185), el cual, por cierto, nunca fue activado; se transforma la naturaleza del Banco Central de Venezuela (artículo 318); o se redefine y se reorganiza la Fuerza Armada Nacional (artículo 328).

El hecho de que se mencionen estos temas no debe entenderse como un desacuerdo con la necesidad de reformar la Constitución para modificarlos, sino como la demostración de una obviedad: son modificaciones del ordenamiento constitucional venezolano que no deberían llevarse adelante por la vía de la simple reforma constitucional, sino por la más democrática de una Asamblea Nacional Constituyente. Por qué no se ha realizado así, sólo los proponentes de la reforma lo pueden conocer. Pero desde la perspectiva jurídico-constitucional no cabe duda alguna.

Dicho esto, tampoco parece de recibo la cínica posición de la oposición, la derecha venezolana, y una importante parte de la opinión pública, que se rasgan las vestiduras porque se utilice una vía que permite opinar a los venezolanos y venezolanas sobre la modificación de su texto constitucional. Cabe recordar que la Constitución de 1961 se ela- 
boró por medio de un cerrado pacto de élites, sin participación alguna de los ciudadanos. Y no podemos olvidar que la derecha, venezolana e internacional, aplaudió con entusiasmo la derogación de la vigente Constitución de 1999 durante el "carmonazo".

Tampoco en otros ámbitos geográficos podemos estar muy contentos de la legitimidad de nuestros procesos constituyentes. Qué decir de la patética inteligentzia española, que ni se inmutó cuando se hurtó a la ciudadanía la elección de una Asamblea Constituyente que rompiera con el franquismo, y entregó dicha función, de facto, al Legislativo ordinario; o el hecho de que en España sea posible modificar importantes partes del texto constitucional -como ocurrió con el artículo 13, aprobado con nocturnidad por las Cortes Generales- sin pedir la opinión de la ciudadanía.

\section{¿Presidente vitalicio en un pais sin propiedad privada?}

Sobre el contenido de la reforma constitucional se han vertido ríos de tinta, aunque no todos parecen haber consultado el texto propuesto. Como ocurre en estos casos, se ha producido una catarata de lugares comunes e incorrecciones que, a fuerza de ser repetidas, han calado en una buena parte de la opinión pública en la que la agresividad de los medios de comunicación bus- ca acabar con cualquier postura de cuestionamiento hacia las verdades mediáticas.

El eje central de la crítica, tanto a nivel interno como internacional, ha insistido en que, supuestamente, la reforma constitucional establecía la perpetuación en el poder del presidente Chávez, por una parte, y por otra en que se abolía la propiedad privada. Ninguna de las dos cosas son ciertas.

La redacción propuesta para el artículo 230, contenida en la reforma, establece que "el periodo presidencial es de siete años. El presidente o presidenta de la República puede ser reelegido o reelegida". Nada más. Es decir, que, con independencia de que el periodo de siete años pueda parecer excesivo -y en constitucionalismo comparado no existen muchos casos similares-, lo cierto es que ni el proyecto busca nombrar presidente vitalicio a Chávez, ni nada por el estilo. Simplemente se adopta un criterio, el de la posibilidad de reelección, ajeno al sistema presidencialista de origen norteamericano, pero consustancial al parlamentarismo europeo: que el jefe del Ejecutivo puede ser elegido tantas veces como lo quiera la ciudadanía ejerciendo su derecho al libre sufragio. No hace falta recordar, en el caso español, que Felipe González fue reelegido en tres ocasiones, y que lo intentó una cuarta aunque las circunstancias se lo impidieron, y a nadie sensato se le ocurriría pensar que se trataba de 
una forma de gobierno autoritaria. Por no hablar de los ejemplos, sin salir de nuestro país, de Manuel Chaves (dieciocho años gobernando Andalucía) o Jordi Pujol (diecinueve años al mando del Ejecutivo catalán).

Es cierto, se dice, que en los sistemas parlamentarios existe la posibilidad de que el Parlamento censure al Ejecutivo y, por lo tanto, caiga el gobierno. Pero también lo es, en primer lugar, que la moción de censura sólo se produce en momentos de particular inestabilidad política, o cuando las elecciones no han propiciado una mayoría suficiente de apoyo al Ejecutivo -aunque lo lógico sería, en ese caso, que no se pudiera formar gobierno más que se le censure-. En los sistemas presidencialistas, como el venezolano, no está prevista la censura al presidente de la República (sí a los ministros), por su calidad de jefe de Estado y jefe de gobierno en una misma persona; pero la Constitución venezolana fue la primera en el mundo en prever la revocación del mandato, mucho más democrática que la moción de censura, donde los ciudadanos pueden, de forma directa, decidir si el presidente permanece o no en el poder (como ocurrió en 2004 en ese mismo país).

Por otro lado, es cierto que la propuesta cuestiona la previsión anterior sobre la propiedad. La redacción propuesta para el artículo
115 de la Constitución vigente, que antes sólo se refería a la propiedad privada, amplía el reconocimiento a otras formas de propiedad pública, social, colectiva o mixta. Pero mantiene la vigencia del derecho de propiedad privada, que es definida como aquella que "pertenece a personas naturales o jurídicas y que se reconoce sobre bienes de uso, consumo y medios de producción legítimamente adquiridos, con los atributos de uso, goce y disposición y las limitaciones y restricciones que establece la ley [...] con fines de utilidad pública o de interés general". Es decir, una redacción similar a la que podemos encontrar en la mayor parte de las constituciones europeas de posguerra. Por cierto, se trata de una regulación que poco tiene que ver con el socialismo clásico, puesto que el proyecto establece que la expropiación de bienes, además de producirse tras el pago de justa indemnización, únicamente podrá formalizarse mediante sentencia firme. ¡Ya quisieran los propietarios de muchos países europeos contar con una regulación similar que limitara la capacidad de expropiación de sus bienes por el Estado!

Por tanto, es fácil percatarse cómo una parte del debate ha estado basado en falsedades, mentiras repetidas hasta la saciedad, y una escandalosa manipulación de la derecha mediática, a la que se ha dejado arrastrar una buena parte de la izquierda europea. 
Una propuesta mejorable

Pero, por otro lado, el hecho de que se haya incurrido en falsedades no significa que la propuesta sea la mejor que haya podido realizarse. Desde un sentido de avance progresista en un proceso de cambio, no lo es.

Vamos a dejar de lado la deficiente redacción técnico-jurídica de la que adolecen no pocos artículos del proyecto de reforma (por ejemplo, cuando se prohíben los monopolios sin especificar que se trata de los privados, lo que es contradictorio con la posterior reserva al Estado de determinados sectores económicos, obviamente en régimen de monopolio -artículo 113-), o algunas erróneas concepciones de algunas instituciones jurídicas (se establece el refrendo del vicepresidente primero de la República para la mayoría de los actos del presidente, que es a quien se atribuye directamente por el pueblo la función ejecutiva, trasladando una institución que tiene su lógica en la mayor parte de los sistemas parlamentarios, donde los jefes de Estado no cuentan con poderes ejecutivos). Los motivos para desconfiar en que la reforma sea la más conveniente están, desde luego, en el fondo de la propuesta.

Para ser honestos, en el proyecto aparecen aspectos que mejoran sustancialmente las previsiones de la Constitución de 1999, pero también otras muchas que significan un evidente retroceso. Las condiciones con que nació el texto constitucional no eran lo suficientemente maduras y, seguramente, ni siquiera posibilitaban un cambio más profundo del que tuvo lugar. Por ello, la profundización en el proceso necesita del cambio constitucional. Ahora bien, ¿son estas modificaciones las que apuntan realmente a un cambio adecuado en el proceso venezolano?

Es innegable, por ejemplo, que se han mejorado claramente previsiones como la del artículo 21, que desarrolla el principio de igualdad, la reducción de la mayoría de edad a los 16 años - una apuesta por la juventud-y la concesión a los extranjeros del derecho al voto, no sólo en las elecciones municipales, como en la actualidad, sino también en las regionales (artículo 64); el reforzamiento de los mecanismos de fiscalización de la financiación de los partidos y las campañas electorales (artículo 67); los derechos laborales, a la seguridad social o la reducción de jornada laboral a 36 horas semanales (Arts. 87 y 90); el derecho de educación para todos (Art. 103); o el fortalecimiento de la autonomía universitaria (artículo 109). También resulta positiva la regulación de los principios de la política exterior del Estado, encaminados a la "no intervención en los asuntos internos, solución pacífica de los conflictos internacionales y el respeto a los derechos humanos y la solidaridad entre los pueblos en la lucha por su emancipación y el 
bienestar de la Humanidad" (artículo 152); así como la incorporación de una cláusula constitucional que permita la generación de mecanismos de integración latinoamericanos, incluida una Confederación (artículo 153).

También son positivas previsiones como la del reforzamiento del control sobre el gasto público, con la creación de las contralorías estadales y municipales (artículos 163 y 176); los principios de funcionamiento del régimen económico y social, basado en criterios de intervención estatal "para garantizar el desarrollo armónico de la economía nacional" (artículo 299); la calificación como actividades reservadas al Estado de la explotación, transporte y almacenamiento de los hidrocarburos líquidos, sólidos y gaseosos (artículo 302); la prohibición de privatizar las empresas estatales que desarrollen actividades reservadas al Estado (artículo 303); y la defensa de la producción agroecológica, que garantice la soberanía alimentaria de Venezuela (artículo 305), prohibiendo el latifundio por ser contrario al interés social (artículo 307). Aunque algunas de estas cosas ya estaban planteadas en la redacción vigente, seguramente en algunas de estas modificaciones deben depositarse las verdaderas inquietudes de los poderes económicos trasnacionales, así como sus correas de transmisión políticas, gubernamentales y mediáticas.

Pero junto con todo esto, algu- nas previsiones del proyecto son innecesariamente complicadas y, en algunos casos, perjudiciales. Resulta incomprensible, por ejemplo, la regulación que se hace de la estructura territorial del poder público, generando múltiples niveles de decisión (artículos 16 y 18), a los que antes se ha hecho referencia, que pueden generar más ineficiencia en la gestión de la cosa pública y que, probablemente, encubren una ausencia de reflexión sobre una reforma a fondo de un modelo nominal de Estado federal inexistente. Si, como parece ser, el federalismo no es útil para un país como Venezuela, simplemente habría que plantearse la sustitución del modelo y la aplicación de otro diferente, más acorde con la realidad venezolana.

Otro ejemplo de poco acertada redacción de la reforma se encuentra en la generación de un nuevo poder público (junto al nacional, estadal o municipal) que se denomina Poder Popular (artículo 136), que apunta hacia la absurda idea de que éste sea un poder más del Estado, en lugar del fundamento del mismo y del conjunto de los poderes públicos. Tampoco es muy lúcida la diferenciación entre diferentes tipos de propiedad (artículo 115), lo que vuelve a conducirnos a la sospecha de una reforma constitucional precipitada y poco reflexionada. Son errores de concepto que, desde luego, merecían una reflexión más profunda.

Más peligroso es el retroceso que 
se experimenta en el concepto de democracia participativa, verdadero sustento del proceso de cambio en Venezuela desde 1998. En ese sentido, el proyecto aumenta sistemáticamente todos los porcentajes de firmas necesarios para promover un mecanismo de participación popular, en algunos casos haciéndolos impracticables pues se exige, por ejemplo, la firma del 30\% de los electores de la circunscripción para activar el referendo revocatorio de cargos públicos (artículo 72), el abrogatorio de leyes y decretos con valor de ley (Art. 74) o la convocatoria de una Asamblea Nacional Constituyente (artículo 348).

Más perniciosa si cabe parece la constitucionalización de las "misiones" (artículo 141). Las misiones son necesarias para evitar burocracias anquilosadas que obstaculizan la implementación de políticas sociales que permitan mejorar las condiciones de vida de la población. Pero su carácter debe ser temporal, hasta que se produzca una reforma de la administración pública. El reconocimiento de las "misiones" como formas estables de gestión supone, en la práctica, la asunción implícita de la incapacidad del gobierno de llevar adelante una adecuada reforma del Estado y, por otro lado, se traduce en la consolidación de un mecanismo donde los sistemas de control presupuestario se debilitan, permitiendo por tanto la proliferación de la corrupción.
Únicamente desde la experiencia concreta venezolana puede verse como positivo el vaciamiento competencial de los estados, transfiriéndose competencias al Estado central o hacia los municipios y comunidades (artículos 156 y 164). Pero resulta inadecuado que esa centralización acabe reforzando la concentración de poderes en manos del presidente de la República (artículo 236).

Tampoco parece particularmente útil la creación de un Consejo Nacional de Gobierno, encargado de coordinar la acción entre el gobierno nacional, los gobiernos estatales y los municipios y órganos del Poder Popular (artículo 185), puesto que ya el Consejo Federal de Gobierno, de funciones similares y eliminado en el proyecto, nunca se activó. Pese a que el Consejo de Estado tampoco fue nombrado nunca, el proyecto altera su composición y lo convierte simplemente en un órgano de consulta del presidente con los demás presidentes de los órganos del Poder Público Nacional (artículo 252).

No resultan muy acertados los mecanismos de selección y elección de los magistrados del Tribunal Supremo de Justicia (264), del Consejo Nacional Electoral (artículo 295), del fiscal general, del contralor general de la República y del defensor del pueblo (artículo 279). En todos estos casos, aunque aparentemente se contemplan mecanismos de par- 
ticipación social, las entidades que deben componer los respectivos comités de postulaciones son elegidas por la mayoría absoluta de la Asamblea Nacional, que es la misma que finalmente elige a dichos funcionarios. Y no parece muy garantista establecer que dichos funcionarios puedan ser removidos, en caso de faltas graves, por la mayoría de los miembros de la Asamblea Nacional (artículos 265, 279 y 296), sin que se determine constitucionalmente qué se entiende por falta grave. El mecanismo puede dar lugar a una discrecionalidad por parte del Parlamento que no siempre será positiva.

Se ha desaprovechado la reforma para crear un verdadero Tribunal Constitucional, encargado de velar por el cumplimiento de la Constitución por el resto de los poderes del Estado, y esas funciones continuarán en manos de la Sala Constitucional del Tribunal Supremo de Justicia, a medio camino entre un sistema de control difuso y de control concentrado de la constitucionalidad.

Aunque es deseable una disminución de la autonomía de los bancos centrales, la reforma plantea que el Banco Central de Venezuela sólo se ocupe de la ejecución de la política monetaria y cambiaria, eliminándose los mecanismos anteriores de coordinación del banco con el Ejecutivo nacional para la determinación de dichas políticas, y se incorpora un ámbito de decisión más directo del Ejecutivo, que alcanza a la administración de las reservas internacionales (artículo 321), sin abandonar como objetivos "evitar la vulnerabilidad de la economía y velar por la estabilidad monetaria y de precios" (artículo 320).

Por último, la redacción propuesta para el artículo 338 elimina las limitaciones temporales para los estados de excepción (con la reforma "durarán mientras se mantengan las causas que los motivaron") y modifica los derechos fundamentales que no pueden ser restringidos o suspendidos durante el periodo de excepción. Además de apartar del listado el derecho de la información, se sustituye la genérica mención aún vigente del derecho al debido proceso por la exclusiva prohibición de que sea suspendido o restringido "el derecho a la defensa, a ser juzgado o juzgada por sus jueces naturales y a no ser condenado o condenada a penas que excedan los treinta años" (artículo 337), dejando fuera de la exclusión otros contenidos del derecho al debido proceso.

Sea cual sea el resultado del referendo, ¿cuál nos parece que tiene que ser la actitud de la dirigencia del proceso bolivariano ante esta encrucijada en que se encuentra?

Con independencia del resultado electoral, parece indiscutible que el gobierno bolivariano debe tomar nota de algunas cuestiones relevantes:

Aunque finalmente los ciudadanos bolivarianos hayan apoyado la propuesta de reforma para no dar un aparente triunfo a la derecha 
golpista, ha quedado puesto suficientemente de relieve el grado de insatisfacción de un sector del chavismo con el rumbo que está tomando el proceso político y social.

Una parte sustancial de los votantes de Chávez piensan que en lugar de hacer política de grandes gestos hay que hacer política de grandes resultados sustentables. Es decir, conseguir que los grandes avances sociales y políticos que se han dado en Venezuela se consoliden y tengan un funcionamiento estable.

Para ello urge llevar a cabo, sin prisas pero sin pausa, un gran proceso de reforma de las administraciones públicas y disminuyendo la alta rotación del personal al servicio de la función pública, que permita garantizar la eficiencia a la administración.

Debe reforzarse el componente de pluralidad dentro del proceso político. Las divergencias en lo táctico y en las soluciones concretas deben entenderse como una riqueza y no como una debilidad.

Debe reforzarse el estudio en detalle de qué Estado se desea como resultado final del proceso bolivariano y planificar que, en el momento políticamente adecuado, se realice una Asamblea Nacional Constituyente que establezca jurídicamente los fundamentos de ese nuevo modelo de Estado ya definido previamente.

Priorizar la consolidación de una economía no dependiente del petróleo, cuestión ésta que, si bien se ha intentado, no se ha conseguido precisamente por la inexistencia de una administración pública que asigne racional y planificadamente los recursos.

Es ahora cuando se está en disposición de definir cuál va a ser el rumbo final del proceso de cambio político-social en Venezuela. De lo que ahora se haga dependerá que mucha gente, dentro y fuera de Venezuela, se mantenga unida e identificada con el mismo o, por el contrario, que entienda que se ha tratado de una nueva oportunidad perdida por la izquierda emancipadora, democrática y socialista.

\section{Conclusión}

Es difícil hacer un balance objetivo que apueste o no por apoyar el proceso de reforma constitucional.

Por una parte, la propuesta era mejorable técnicamente y de fondo. Incorpora elementos extremadamente complejos, e impropios de un cambio de avanzada. Y ya que se da por supuesta la apropiación por el pueblo de la Constitución -como ocurrió con el texto de 1999- debe procurarse la mayor claridad posible, sin que vaya en detrimento de la calidad jurídica.

Además, es un proyecto que no cumple con las expectativas de profundización del cambio del modelo económico y social. Aparecen mu- 
chos conceptos que, al menos en la propuesta de reforma, no están suficientemente concretados. No se ha avanzado en las garantías de los derechos económicos y sociales ni en los mecanismos concretos de transformación del modelo de producción.

Por otra parte, el proyecto no sólo no profundiza en la democracia participativa, sino que endurece varias condiciones para su aplicación. Grave error, especialmente cuando la diferencia entre el proceso de cambio venezolano y otros procesos sociales ha sido justo ésa: la legitimidad que proporciona la partici- pación. Se pudo haber apelado, y no se hizo, al mecanismo adecuado para la realización de los cambios: la Asamblea Constituyente.

Todo ello no significa que sea un proyecto totalitario, propio de una dictadura, ni contrario a los principios y valores de la democracia, como ha querido ser vendido por la derecha venezolana e internacional y el sistema mediático. Simplemente es un proyecto de reforma inadecuado para el momento histórico en que se da. Muchas alforjas para un tramo tan corto, cuando necesitaremos muchas más para cruzar el verdadero desierto.

O PIN I ÓN

Este comentario trata de combatir la creencia de que la representación política está ligada de una manera más o menos efectiva a los ideales de democracia. Así es común escuchar que aquélla no funciona porque pareciera no terminar de sincronizarse con ésta, sin considerar que se trata de incompatibilidades intrínsecas. A partir de esto el autor propone repensar el contenido de la representación política para darle un significado más cercano a la práctica, así como encontrar un nuevo paradigma del concepto.

\section{La representación política y la democracia (consideraciones para un debate actual en México) \\ José Luis Mendoza Tablero* \\ Introducción \\ $\mathrm{N}^{\text {os }}$ movemos en un mundo poco confiado en la política $y$, en su caso particular, en la repre- sentación política, ${ }^{1}$ la situación no es mejor. Se dice que los partidos

\footnotetext{
* Maestro en análisis regional. Catedrático del lnstituto de Ciencias Jurídicas de Puebla.

${ }^{1}$ En ocasiones me referiré simplemente a la representación, pero debe entenderse representación
} política.}

